Note

\section{Deodorizing of Sludge Solids by Actinomycetes ${ }^{\dagger}$}

\author{
Ayaaki IsHIZAKI, \\ Harcharan Singh SIDHU, ${ }^{*}$ Chin-lam LIM** \\ and Wai-heng $\operatorname{Lim}^{* *,+\dagger}$ \\ Department of Food Science and Technology, \\ Faculty of Agriculture, Kyushu University, \\ Hakozaki, Higashi-ku, Fukuoka-shi 812, Japan \\ ${ }^{*}$ School of Biological Science, \\ and ** Department of Food Science and Technology, \\ School of Applied Science, Universiti Sains \\ Malaysia, Minden, Pulau Pinang, Malaysia
}

Received July 28, 1986

Malaysia, a member of Association of Southeast Asian Nations, is becoming industrializes and therefore faces pollution like other developed countries. The Malaysian government passed the Environmental Quality Act 1974, which has been enforced in its entirely since 1981 after the addition of schedule for intermediate stages of enforcement. According to the Act, the Biological Oxygen Demand limit for industrial waste water discharged into rivers of the group described as "Standard B" (not upstream of water supply intakes for human drinking) shall not exceed $50 \mathrm{ppm}$. Methods of the waste water treatment using activated sludge can meet this BOD limit except for the problem of the inactivation of sludge. Without proper treatment, the dumping of excess sludge can give rise to unpleasant odors and unsanitary conditions.

Much chicken dung is used by vegetable farmers in this country and we thought that excess sludge might be recycles as organic fertilizer as part of an integrated system for the treatment of waste water for food industries in Malaysia. Deodorization is the key technology for this process. Various microorganisms have been used for deodorization, ${ }^{1 \text { 6) }}$ the actinomycetes are effective, especially for solid organic wastes such as pig feces and poultry droppings. ${ }^{712)} \mathrm{We}$ studied the use of these organisms to remove the unpleasant smell from the drying process of excess sludge from the activated sludge water treatment system of malaysian food industry.

Thirteen strains of Actinomycetes were isolated from soil in and around the factory premises of Ajinomoto
Malaysia. Agar plates consisting of activated sludge extract $(60 \%$ by vol.), nystatin $(30 \mathrm{mg} /$ liter $)$, cycloheximide $(30 \mathrm{mg} /$ liter $)$ and agar-agar $(20 \mathrm{~g} /$ liter $)$ were sterilized at $120^{\circ} \mathrm{C}$ for $30 \mathrm{~min}$. The preparation of the activated sludge extract is shown in Fig. 1.

One gram of soil was suspended in $10 \mathrm{ml}$ of sterile water and shaken for $10 \mathrm{~min}$. The soil suspension was spread on the surface of an agar plate, which was then incubated for $48 \mathrm{hr}$ at $50^{\circ} \mathrm{C}$ for monocolony isolation. The 13 strains isolated were used for the monoculture experiment to evaluate their deodorizing potential. Inocula of individual strains were prepared by the culturing of a loopful of a slant stock culture in a tryptone-yeast extract broth $24 \mathrm{hr}$ in a shaking flask $(170 \mathrm{rpm})$ at $50^{\circ} \mathrm{C}$. Inocula were transferred to a modified sludge medium (MSM) that consisted of powdered activated sludge ( $15 \%$ moisture; $18 \mathrm{~g})$, sawdust of a malaysian timber mill $(2 \mathrm{~g}), 1 \mathrm{~mm}$ L-alanine $(2 \mathrm{ml}),{ }^{13)}$ $10 \mathrm{mM} \mathrm{Na}_{2} \mathrm{HPO}_{4}(2 \mathrm{ml})$. The moisture of the mixture was adjusted to $55 \%$ with $40 \mathrm{ml}$ of distilled water to start the growth of the actinomycetes. The moisturized mixture was

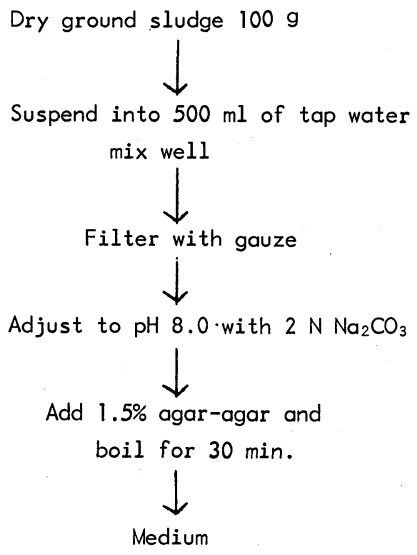

FIG. 1. Treatment of the Activated Sludge Extract for Medium Preparation.

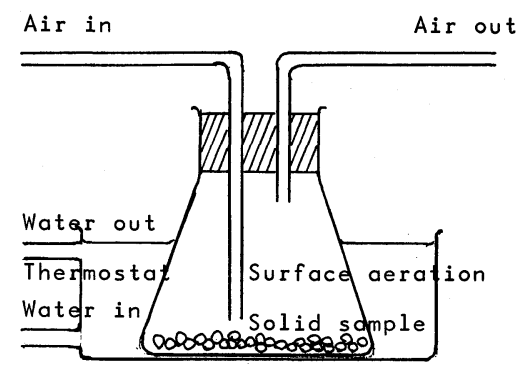

Fig. 2. Apparatus for Blowing Air over the Surface.

$\dagger$ Part of this paper was presented at the 7th Malaysian Microbiology Symposium held at Universiti Sains Malaysia, Pulau Pinang, Malaysia on 19 November 1984.

${ }^{\dagger \dagger}$ Present address: Ajinomoto Malaysia Bhd., Kuala Lumpur, Malaysia. 

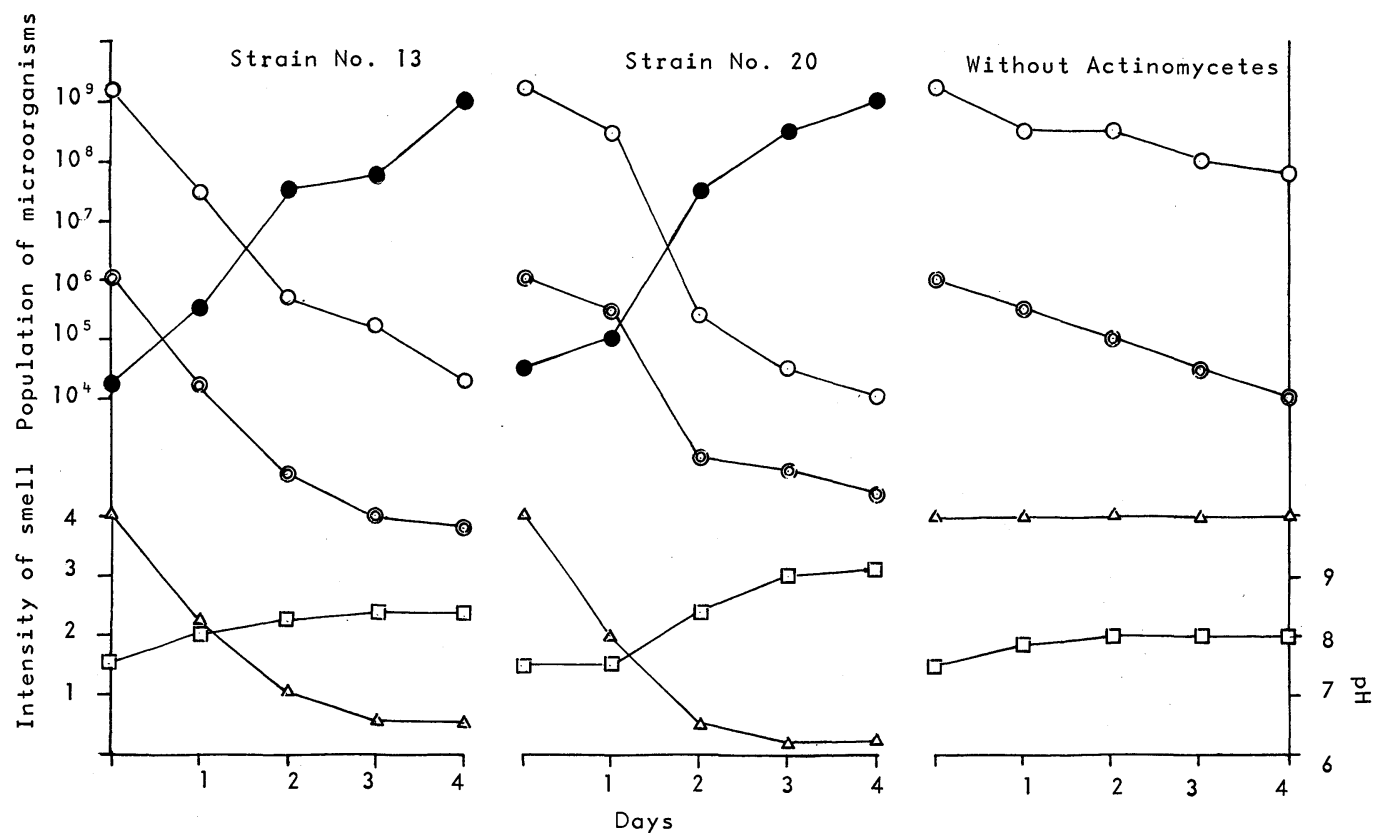

FIG. 3. Microbial Population, Unpleasant Smell and pH during Culture.

- - , actinomycetes; $-\mathrm{O}-$, bacteria; $-\mathrm{O}-$, fungus; $-\triangle-$, smell; $-\square-$, pH.

sterilized in an autoclave at $120^{\circ} \mathrm{C}$ for $15 \mathrm{~min}$. Four grams of incubated MSM $(20 \% \mathrm{w} / \mathrm{w}$ on a dry basis) were then transferred to $16 \mathrm{~g}$ of sundried sludge (approximately $15 \%$ moisture) to make the unsterilized sludge preparation for the deodorization test. Ten percent sawdust was mixed with unsterilized powdered sludge and the initial moisture was adjusted to $55 \%$ with distilled water. These preparation and the control (without inoculum) were kept at $50^{\circ} \mathrm{C}$ for 4 days with air blowing over the surface of the medium (Fig. 2). During incubation, the odor of the sample was evaluated by panelists selected from the laboratory staff.

Microorganisms were enumerated on nutrient agar $(\mathrm{pH}$ 7.4) for bacteria, nutrient extract agar acidified with lactic acid to $\mathrm{pH} 3.5$ for fungi, and sludge extract agar with nystatin $(30 \mathrm{mg} /$ liter $)$ and cycloheximide $(30 \mathrm{mg} /$ liter $)$ for actinomycetes.

Only two strains (Nos. 13 and 20) were deodorizing. Their data are shown in Fig. 3 with profiles of microbial growth. The data suggest that living cells of bacteria and fungi became fewer while actinomycetes increased during the incubation.

We did gas chromatography model 163 (Hitachi) with Unisole $4005 \%$ and Uniport S 60/80 for the glass column 163 (i.d. $3 \phi \times 2 \mathrm{~m}$ ) operating at $155^{\circ} \mathrm{C}$ with a flow rate of nitrogen as the carrier gas of $30 \mathrm{ml} / \mathrm{min}$ to identify the volatile fatty acids emitted during the drying of the sludge. Samples for gas chromatography were prepared as shown in Fig. 4. The results are shown in Fig. 5, and acetic acid, propionic acid, $n$-butyric acid, isobutyric acid, and iso-

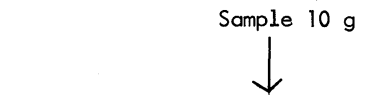

Add $25 \mathrm{ml}$ of dichloromethane and leave overnight<smiles>CCC</smiles>

Centrifuge at $3000 \mathrm{rpm}$ for $10 \mathrm{~min}$.

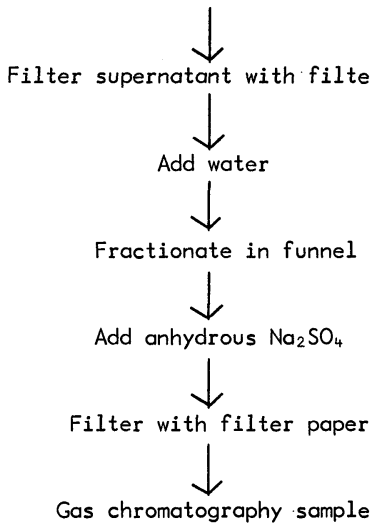

FIG. 4. Sample Preparation for Gas Chromatography.

valeic acid were isolated. The peaks of these compounds after gas chromatography were absent in a sludge sample treated with strain No. 20. The same was found with the strain of actinomyces described as HIR 50 provided by Professor S. Hayashida of the University of Kyushu. 


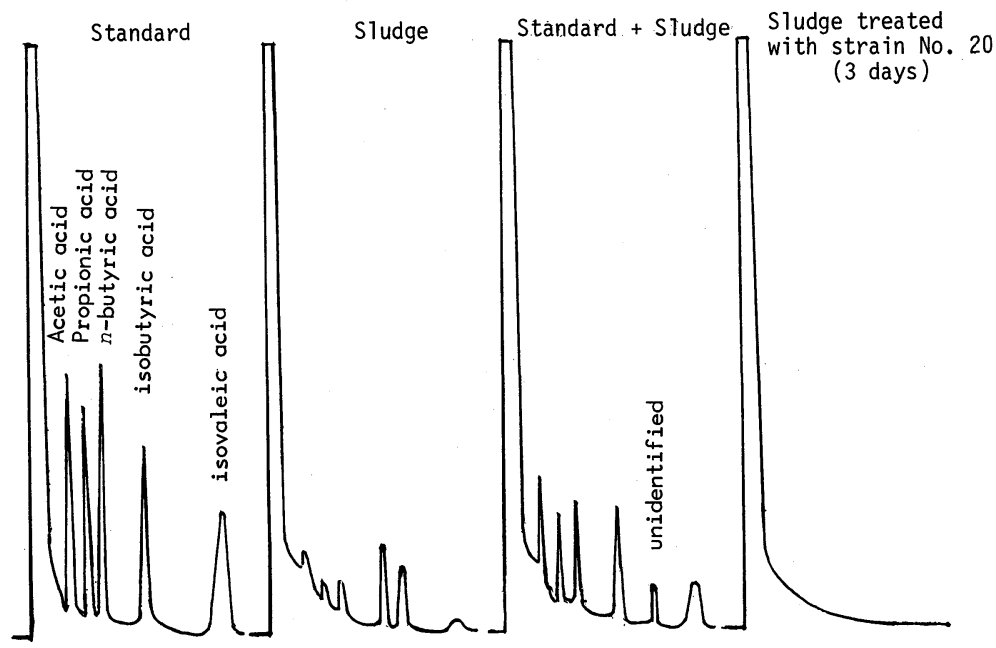

FIG. 5. Gas Chromatogram of Volatile Fatty Acids.

Volatile fatty acids of a low molecular weight were the main chemical component of the unpleasant smell.

Acknowledgments. This paper is dedicated to the memory of $\mathrm{Mr}$. $\mathrm{Ku}$ Shahdan $\mathrm{Ku}$ Hassan, a microbiologist at Ajinomoto Malaysia Bhd., who passed away while this work was in progress.

The authors thank Professor Shinsaku Hayashida of the University of Kyushu for the type culture of Thermomonospora viridis HIR 50 as well as for his continuing guidance and encouragement. We also thank $\mathrm{Mr}$. Abdul Jalil Abu Baker of the School of Applied Science of the Universiti Sains Malaysia and Mr. Esmail Malek of Ajinomoto Malaysia Bhd.

\section{REFERENCES}

1) K. Hata, T. Maruoka and T. Hata, Japanese Patent 7718879 (1977) [C.A., 86, 187707 (1977)].

2) O. Hata, Japanese Patent 77154526 (1978) [C.A., 88, 158296 (1978)].

3) Y. Tanaka, S. Hayashida and M. Hongo, Hakko Kogaku Zasshi, 54, 333 (19.76).
4) Y. Tanaka, S. Hayashida and M: Hongo, Hakko Kogaku Kaishi, 55, 134 (1977).

5) Y. Fujio, Y. Ohtomi, S. Hayashi and S. Ueda, Hakko Kogaku Kaishi, 56, 304 (1978).

6) Y. Ohta and Y. Kuwada, Hakko Kogaku Kaishi, 61, 195 (1983).

7) Y. Tanaka, T. Tanaka, N. Nanri and S. Hayashida, Hakko Kogaku Kaishi, 56, 788 (1978).

8) Y. Ohta and M. Ikeda, Appl. Environ. Microbiol., 36, 487 (1978).

9) Y. Ohta and M. Ikeda, Nippon Nōgeikagaku Kaishi, 53, 277 (1979).

10) Y. Ohta, M. Ikeda and Y. Hemmi, Hakko Kogaku Kaishi, 57, 372 (1979).

11) S. Hayashi, Y. Fujio and S. Ueda, Hakko Kogaku Kaishi, 58, 197 (1980).

12) K. Arima and G. Tamura, "Seibutsu niyoru kankyoujooka (Microbiology for Environment Cleaning)," University of Tokyo Press, Tokyo, 1980, pp. $243 \sim 251$.

13) H. S. Sidhu and P. M. Sivalingam, Abstracts of Papers, 6th Malaysian Microbiology Symposium, Ipoh, Malaysia, Sept. 1984. 